\title{
Boletín Criminológico
}

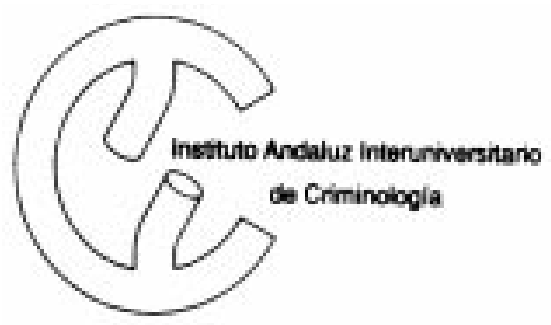

Director: Per Stangeland

Coordinadora: Elisa García España

Publicado por la Sección de Málaga del IAIC

Edificio Institutos de Investigación, Universi-

dad de Málaga. Campus de Teatinos, 29071

MALAGA

Tel:(95) 2132325 - Fax:(95) 2132242

Depósitolegal:MA857/1996ISSN:1137-2427

www.uma.es/estudios/propias/criminologia

\section{El Boletín Criminológico: Información actualizada sobre delincuencia y justicia}

En este Boletín publicamos unos resultados preliminares del proyecto «Estadísticas sobre la delincuencia en Andalucía» subvencionado por la Junta de Andalucía y realizado en colaboración con el Departamento de Estadística de la Universidad de Málaga. El director de la investigación es Juan Ignacio Domínguez y el presente trabajo ha sido redactado por Per Stangeland, Elisa García y $\mathbf{M}^{\mathrm{a}}$ Victoria Márquez. Nuestra gratitud a todos los Juzgados de Málaga y al grupo de estudiantes del Instituto de Criminología compuesto por Francisco José Alvarez, Juan Andrés Bermejo, Lelys Gallegos, Inmaculada Núñez, Cecilia Pérez, Fernando Piernavieja y Eugenio Vázquez.

\section{METODOS}

Los Secretarios de Juzgado envían trimestralmente un informe al Consejo General del Poder Judicial con los que se elaboran las estadísticas judiciales. Por ello, para la recogida de información, se han usado los libros del Registro General del año 1992 de los cuarenta Juzgados de Instrucción de la provincia de Málaga y de Melilla. Del total de los casos registrados se sacó una muestra estratificada, eligiendo arbitrariamente un $1 \%$ de los asientos. El tamaño de la muestra ha sido de 1.541 casos, lo cual representa un $1 \%$, aproximadamente, de los 161.954 casos contabilizados en la Memoria del Consejo General del Poder Judicial para Málaga.

\section{FICHA TECNICA}

El margen de error varía con la frecuencia; por ejemplo, en el caso de las comparecencias y denuncias donde la frecuencia es del $3.5 \%$, el error muestral es de $0.91 \%$, es decir, que la cifra real oscila probablemente entre el $2.59 \%$ y el $4.41 \%$.
DISCREPANCIAS ENTRE ESTADISTICAS POLICIALES Y JUDICIALES

El volumen de delincuencia en España es difícil de averiguar, pues no existen estadísticas que muestren su frecuencia real. Fl Ministerio del Interior no publica oficialmente datos sobre los sucesos presuntamente delictivos que llegan a conocimiento de la policía. Sin embargo, de vez en cuando, se presentan datos procedentes de la Policía Nacional y de la Guardia Civil que reflejan los hechos conocidos por estos dos Cuerpos. En 1992, la cifra aportada a nivel nacional era de 934.070 .

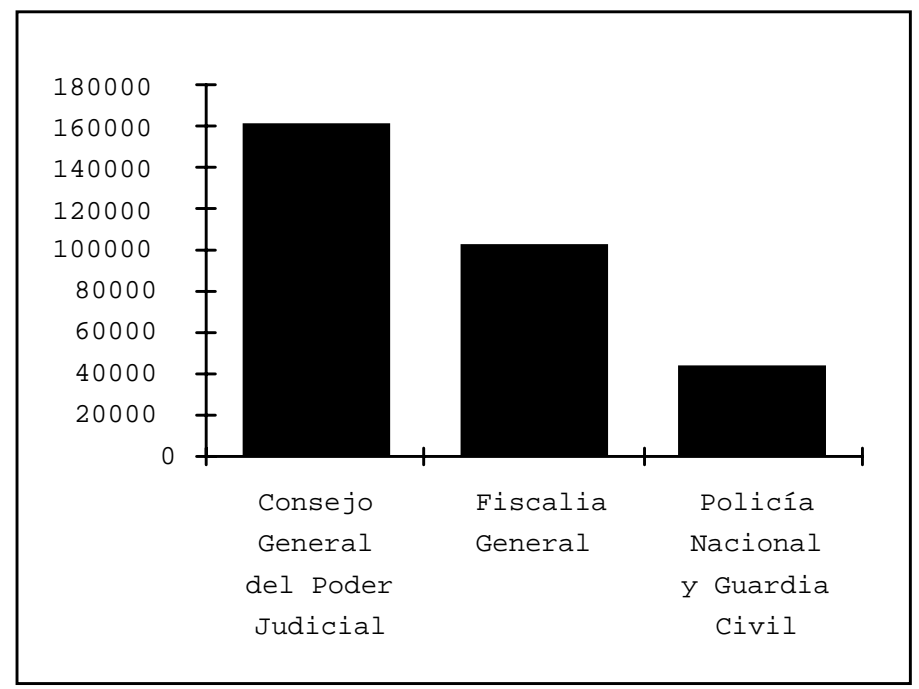

\section{Boletín Criminológico $\quad N^{o} 2 . \quad$ Julio-Agosto 1994 Página 1}


Según el procedimiento penal español, el que instruye las causas es el juez, por lo que la policía tiene la obligación de poner en conocimiento de los Jueces de Instrucción todos los hechos susceptibles de ser calificados como delitos o faltas, así como todo tipo de actuaciones para las que se requiera autorización judicial. Todas las causas que se presentan en los juzgados se recogen y publican en las estadísticas judiciales.

El principal problema que nos encontramos con tales estadísticas es su total desajuste con los datos aportados por el

\section{VARIABLES}

Las variables utilizadas para el análisis de los asientos de los libros de registro han sido las siguientes: procedencia, delito, lugar y destino. Por procedencia nos referimos a la instancia que motiva la apertura de unas diligencias. Serían las siguientes: Policía Nacional, Guardia Civil, Policía Local, parte facultativo, turno, indeterminada, denuncia, comparecencia y resto. En cuanto al delito, son todos aquellos hechos que presuntamente son susceptibles de ser calificados como delito o falta, además de otras circunstancias que, sin tener tal calificación jurídica, requieren de conocimiento judicial. La variable lugar incluye las distintas poblaciones de cuyos juzgados se ha sacado la muestra; a saber, Málaga capital, Fuengirola, Marbella, Estepona, Melilla, Torrox, Ronda, Antequera, Archidona, Velez-Málaga y Coin. Se entiende por destino los distintos tipos de diligencias que se abren segœn los casos, como diligencias previas, diligencias indeterminadas, juicios de faltas y resto.
Ministerio del Interior, ya que en la estadística judicial de 1992 se arrojaba una cifra de causas (2.234.328) en España que duplicaba la aportada por la policía. Esa misma tendencia la encontramos en la provincia de Málaga ya que, según los datos que aparecen en la Memoria del Consejo General del Poder Judicial habría 161.954 delitos, según el Fiscal General
102.900 y según la policía 43.471. Tal desfase en los datos nos parece excesivo y consideramos conveniente una aclaración, pues de lo contrario se produce una pérdida de credibilidad en las estadísticas de tales Instituciones.

Lo esperado en la tramitación de expedientes administrativos es que desaparezcan o se archiven algunos de ellos antes de

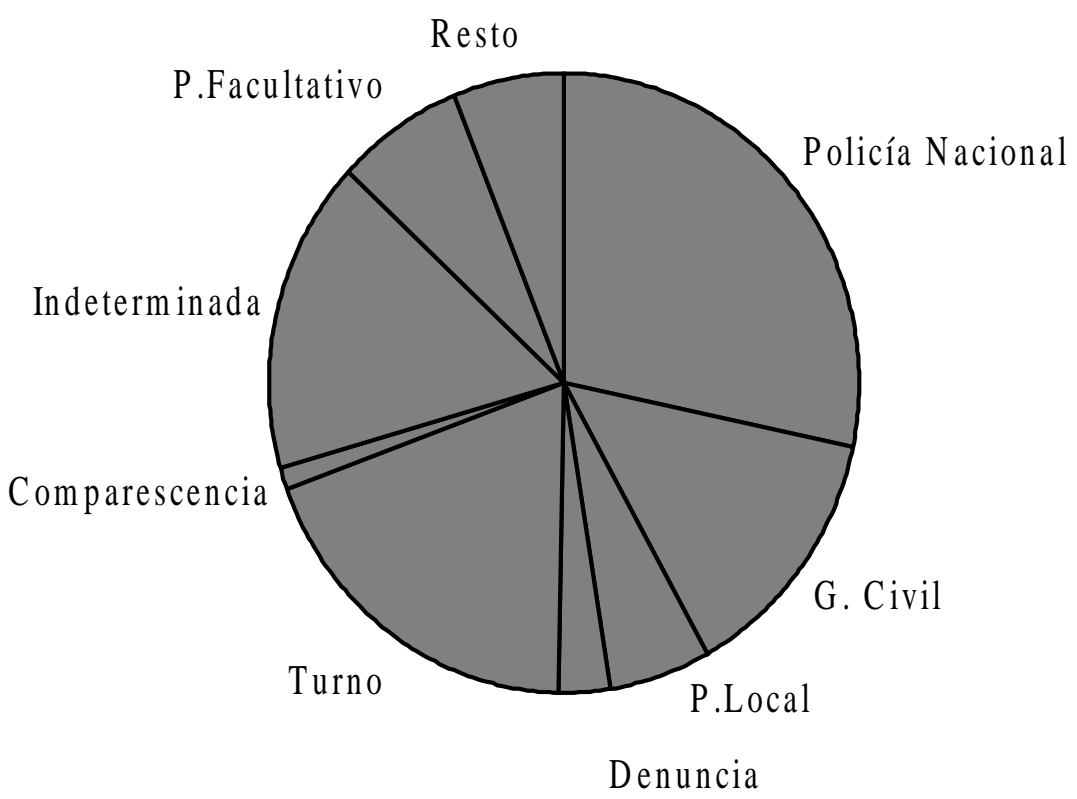

\section{Título de Experto Universitario en Criminología}

El Instituto Andaluz Interuniversitario de Criminología de la Universidad de Málaga imparte sus estuduios de Expero Universitario en Criminología cuya duración es de tres años.

Los interesados deben de haber realizado el primer ciclo de estudios universitarios o bien, teniendo aprobada la selectividad o equivalente, pertenecer a los cuerpos y fuerzas de Seguridad del Estado, Guardia ,Civil, Policía Local, Administración de Justicia, Instituciones Penitenciarias o ser auxiliares de investigador privado.

Todo tipo de información sobre el contenido y estructura del título y las condiciones de ingreso se puede obtener en la secretaría del Instituto (Facultad de Derecho de la Univerasidad de Málaga) Teléfono 2132325

\section{Boletín Criminológico $\quad N^{o} 2 . \quad$ Julio-Agosto 1994 Página 2}


llegar al órgano superior; por el contrario, en el caso que nos ocupa, las causas puestas en conocimiento de los jueces de Instrucción son más del doble de las presentadas por la policía. Esta discrepancia ha sido comentada en revistas especializadas y también por la prensa en varias ocasiones, como fue el caso del Sur de 19 de mayo de 1994 y El Pais de 23 de mayo del mismo año.

El objetivo, por tanto, de la investigación que se estállevando a cabo al respecto y de la que en este Boletín adelantamos da-

SISTEMA DE TRABAJO EN LOS JUZGADOS

Cada Juez es un órgano independiente con su correspondiente Secretario Judicial. En las ciudades con muchos juzgados cada uno de ellos tiene que hacer guardia de manera rotativa y periódica. Las denuncias que se interponen en un determinado día se hacen ante el Juzgado que dicho día esté de guardia. Esto podría dar demasiado trabajo al juzgado que estuviera de guardia un día en el que ocurrieran muchas incidencias. Por ello, existen unas normas de reparto entre los juzgados con el fin de compensar el trabajo entre ellos. En Málaga, los casos ocurridos con 72 horas de antelación a su presentación en el juzgado de guardia son registrados como indeterminadas e inmediatamente remitidos al Turno para su reparto. Mediante ese turno, es enviado a otro juzgado en donde se volverá a registrar, pero en este caso como diligencia previa con procedencia del turno. Esto hace que un caso sea registrado dos veces y, por lo tanto, contabilizado dos veces por las estadísticas judiciales. tos provisionales, es el de intentar aproximarnos a las posibles causas del importante desfase numérico que existe entre los casos que anualmente son investigados y comunicados por la policía y las diligencias abiertas en sede judicial.

\section{RESULTADOS}

De los 1.541 asientos contrastados, más del $63 \%$ aparece registrado como diligencias previas (véase la tabla). Esta cifra, en términos absolutos y multiplicada por 100 (98.500), es muy próxima a la aportada por el Fiscal General (102.000). Esto explica el porqué el Fiscal General contabiliza menos delitos que el Consejo General del Poder Judicial, ya que los datos del Fiscal General sólo proceden de las diligencias previas. Un $25.6 \%$ son registradas como diligencias indeterminadas, las cuales no siempre están encaminadas a la averiguación de un hecho delictivo sino que en ellas también se incluyen las órdenes de busca y captura y las solicitudes de actuaciones por parte de las fuer- zas policiales para las que la Ley exige autorización judicial. Estas diligencias indeterminadas suelen dar duplicidad en las estadísticas judiciales, ya que es comœn que un hecho delictivo así registrado por un órgano judicial en funciones de guardia se remita al Turno, según las normas de reparto,correspondiendo la instrucción de la causa a otrojuzgado que también registra, normalmente como diligencia previa, dicha entrada.

En cuanto a la procedencia se observa que los partes facultativos nos dan también un motivo de duplicidad e inflan de manera exagerada las cifras debido a que en un accidente de tráfico, por ejemplo, en el que se ven involucrados varios coches y lesionadas 18 personas, si las víctimas son tratadas en diferentes hospitales, cada uno de ellos dará su parte en juzgados distintos dependiendo de la localidad en que se encuentren. Además cada particular puede, por su parte, interponer una denuncia por lo sucedido. De esta manera un accidente puede registrarse en diez juzga-
DILIGENCIAS

$\begin{array}{lrrrrrr}\text { PROCEDENCIA } & \text { Prev } & \text { Indet } & \text { Falta } & \text { Resto } & \text { Total } & \% \\ \text { P. Nacional } & 520 & 142 & 36 & 2 & 700 & 45.4 \\ \text { G.Civil } & 72 & 28 & 13 & 1 & 114 & 7.4 \\ \text { TOTAL } & 592 & 170 & 49 & 3 & 784 & 52.8 \\ \text { P.Local } & 32 & 17 & 115 & 0 & 64 & 4.2 \\ \text { P. facultat. } & 46 & 13 & 25 & 0 & 208 & 13.5 \\ \text { Denuncia } & 18 & 21 & 1 & 0 & 40 & 2.6 \\ \text { Comparec. } & 5 & 9 & 0 & 0 & 14 & 0.9 \\ \text { Resto } & 34 & 15 & 6 & 8 & 63 & 4.1 \\ \text { Turno } & 140 & 10 & 24 & 1 & 175 & 11.4 \\ \text { Indefinida } & 118 & 15 & 30 & 0 & 163 & 10.6 \\ \text { Total } & 985 & 394 & 150 & 12 & 1541 & 100 \% \\ \text { \% } & 63.9 & 25.6 & 9.7 & 0.8 & 100 \% & \end{array}$

\section{Boletín Criminológico $\quad N^{o} 2 . \quad$ Julio-Agosto 1994 Página 3}


dos distintos, ignorando cada uno de ellos la extensión total del suceso.

Sorprende que en los juzgados aparezcan registrados un número muy superior de asuntos procedentes de la policía que los que la policía realmente contabiliza. Una explicación de tal desfase puede deberse a las denominadas «ampliaciones de diligencias». La policía pone en conocimiento del juzgado un asunto de su interés que

\section{RESUMEN DE LA ES- TADISTICA JUDICIAL}

-Aproximadamente la mitad de las diligencias proceden de los Cuerpos Policiales.

-Sólamente un 3.5\% de las diligencias se originan por un particular que se dirige personalmente o por escrito, al juzgado.

-Otro $13.5 \%$ de los casos tienen su origen en un parte médico sobre accidentes de tráfico, domésticos o laborales, suicidios, lesiones, etc. Sin embargo, pocos de estos casos dan lugar a una investigación criminal.

-De todos los casos registrados en la estadística judicial sólo un $64 \%$ da lugar a unas diligencias previas.

-Aproximadamente la mitad de los casos contabilizados en la estadística judicial son duplicidades. se está investigando. El juzgado lo registra. En el transcurso de la investigación la policía obtiene más información, que incluye en el caso en cuestión; sin embargo, al dar conocimiento al juzgado, esta nueva información de un hecho anterior se inscribe con un nuevo nœmero de registro y posiblemente en un juzgado distinto del anterior, denominándose ampliación de diligencias de procedencia policial, normalmente incoada como diligencia indeterminada. Si eliminamos los casos ya registrados, atendiendo unicamente a las diligencias previas, sigue existiendo discrepancia entre ambas estadísticas. Sólo las diligencias previas procedentes de la Policía Nacional y de la Guardia Civil serían, en términos absolutos, 59.200 siendo muy superior a la cifra que ellos aportan (43.000).

\section{CONCLUSION}

El error existente entre las estadísticas policiales y judiciales tie- ne su principal causa en el proceder de los Juzgados, ya que casi todo tipo de comunicaciones entre ellos y otras instancias se registra como un nuevo caso. Por tanto, de las estadísticas judiciales no podemos inferir el volumen de delincuencia existente en España aunque si nos arrojan datos sobre el volumen de trabajo en los juzgados. Tal vez, contabilizando sólo las diligencias previas de determinada procedencia (cifras en rojo de la tabla anterior) nos aproximemos a la criminalidad real .

La estadística interna policial también tiene sus errores y puede ser que algunos casos no lleguen a ser contabilizados. Sin embargo, no sufre las duplicidades de la estadística judicial.

Por ello, teniendo que elegir entre ambas estadísticas, la policial da una imagen más fiable del volumen de la delincuencia. En la œltima fase del proyecto nos centraremos en la validez de esta estadística.

El Boletín Criminológico da un breve resumen de trabajos de investigación llevados a cabo en la Sección de Málaga del I.A.I.C, Facultad de Derecho, Campus de Teatinus, 29071 MALAGA. Se edita un boletín cada mes y la subscripción es gratuita.

Quiero recibir el boletín Criminológico

Nombre

Cargo

Dirección

\section{Boletín Criminológico $\quad N^{o} 2 . \quad$ Julio-Agosto 1994 Página 4}

